\title{
FATIGUE LIFE ENHANCEMENT OF WELDED STEEL-STEEL COMPOSITE DURING CRACK GROWTH FROM WEAK TO STRONG STEEL: AN EXPERIMENTAL VALIDATION
}

\author{
Sunil Bhat ${ }^{1, a}$ and V.G. Ukadgaonker ${ }^{2, b}$ \\ ${ }^{1}$ School of Mechanical and Building Sciences, V.I.T., Vellore - 632014, India \\ ${ }^{2}$ Department of Mechanical Engineering, I.I.T., Bombay - 400076, India \\ a sbbhat@rediffmail.com b vgu@me.iitb.ac.in
}

Keywords: Alloy steel, bimetallic, cohesive zone, composite, crack, fatigue, maraging steel, strength mismatch, weld

\begin{abstract}
Strength mismatch effect across weld interfaces, generated by welding weak and strong steels, influences fatigue and fracture properties of a welded bimetallic composite. Advancing fatigue crack tip in weak parent steel is shielded from the remote load when it reaches near the interface of ultra strong weld steel. Entry of crack tip plasticity into weld steel induces load transfer towards weld which dips crack growth rates thereby enhancing the fatigue life of the composite. A computational model for fatigue life prediction of strength mismatched welded composite under $K$ dominant conditions is validated by experimental work in this paper. Notched bimetallic compact tension specimens, prepared by electron beam welding of weak alloy and strong maraging steels, are subjected to fatigue testing in high cycle regime.
\end{abstract}

\section{Introduction}

Bimetallic composites have shown considerable promise in life enhancement and material and weight optimization of engineering structures with the advent of a) welding processes like explosive cladding and diffusion bonding that are capable of joining dissimilar metals with good bond strength and b) efficient coating technologies. Their concepts, culminating in functionally graded materials, have been successfully tested in aerospace propulsion engines, pressure vessels, gas turbine disks, thin films and coatings, etc. In view of their high utility potential, their fatigue and fracture aspects assume lot of importance especially in load bearing applications. Although literature in this field exists, work still needs to be done towards establishment of fatigue life prediction methodologies of these composites which calls for validation of computational models by experiments. This paper is a step forward in that direction.

Literature survey indicates that the fatigue crack tip in weak steel is shielded from the remote load when it reaches near a thin interface of strong steel and that the effective near tip $J$ integral is smaller than the remote $J$ integral value [1]. These $J$ integrals have hitherto been obtained numerically by finite element analysis. A computational model based upon the concept of crack tip stress intensity parameter is employed in the present work for theoretical treatment of the fatigue crack in a welded composite under $K$ dominant conditions. The model is validated by experiments. A thick weld composite prepared by electron beam welding of weak alloy and strong maraging steels is employed in experimental work.

\section{Theoretical review}

High stresses develop ahead of the crack tip resulting in material plastic strain. Refer Fig. 1. The crack tip zone, comprising process and plastic regions, is commonly referred to as the yield zone. Dugdale [2] modeled the yield zone as a cohesive zone subjected to constant closing cohesive stresses, $\sigma$, equal to material yield strength, $Y$, in plane stress condition. These stresses are assumed as $\sqrt{3} Y$ in plane strain condition.

Refer Fig. 2. Ultra strong weld, $W$, obtained by welding weak parent steel, $A$, and strong interface steel, $B$, results in weld interfaces I and II. Effect of weld interface I is not felt by fatigue crack tip in parent steel till its distance, $a$, from the interface fulfills the condition, $a>\Delta r$, where 
Dugdale's cyclic cohesive zone length, $\Delta r$, under cyclic applied stress intensity parameter, $\Delta K_{\text {applied }}$, is given by $\Delta r=\frac{\pi}{8}\left(\frac{\Delta K_{\text {applied }}}{2 \sigma^{4}}\right)^{2}$. As the crack tip grows and reaches near weld interface I such that $a<\Delta r$, spread of cohesive zone across the interface results in load transfer towards weld steel because of its higher yield strength. This induces a diminishing or shielding effect of load over the crack tip. As the result, the magnitude of stress field and cyclic stress intensity parameter at the crack tip, $\Delta K_{\text {tip }}$, drops resulting in dip in crack growth rates when compared with the values at crack tip in uni-material body made of parent steel alone.

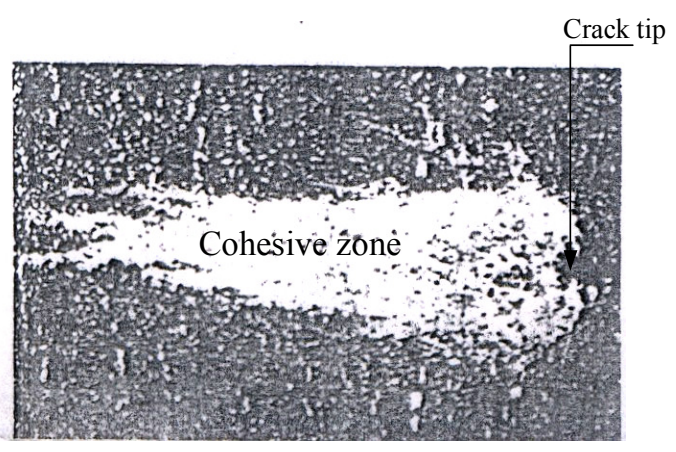

Fig. 1 Crack tip cohesive zone

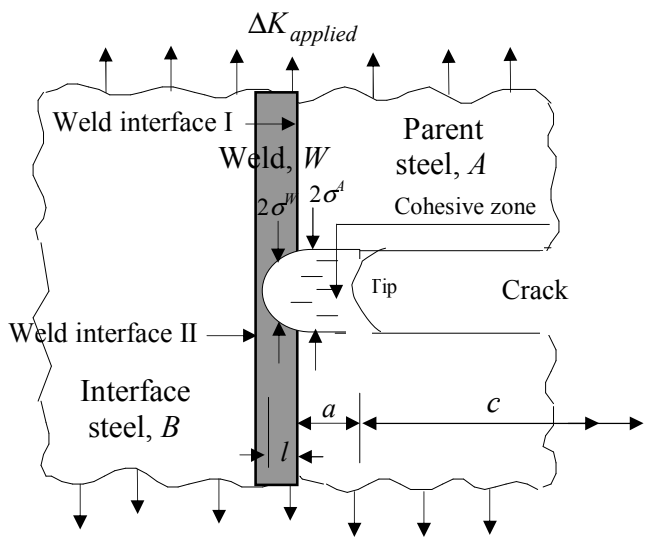

Fig. 2 Fatigue crack tip near weld interface

The computational model [3] based upon Dugdale's cohesive zone criterion to obtain $\Delta K_{t i p}$ at the tip of a Mode I fatigue crack in linear elastic regime near elastically matched weld interface I with the cohesive zone having extended into weld by distance, $l$, is as follows:

$$
\begin{aligned}
& \frac{\Delta K_{\text {tip }}^{2}}{8 \sigma^{A}}=\left\{\Delta K_{\text {applied }} \sqrt{\frac{2}{\pi}(a+l)}-\frac{2 \sigma^{A}}{\pi}[2(a+l)]+\frac{2\left(\sigma^{W}-\sigma^{A}\right)}{\pi}\left[a \ln \left(\frac{\sqrt{(a+l)}+\sqrt{l}}{|\sqrt{(a+l)}-\sqrt{l}|}\right)-2 \sqrt{l(a+l)}\right]\right\} \\
& \Delta K_{\text {applied }}=4 \sigma^{A} \sqrt{\frac{2(a+l)}{\pi}}+4\left(\sigma^{W}-\sigma^{A}\right) \sqrt{\frac{2 l}{\pi}}
\end{aligned}
$$

Eqs. (1) and (2) are solved numerically for unknowns $l$ and $\Delta K_{\text {tip }} . \Delta K_{\text {tip }}<\Delta K_{\text {applied }}$ because $\sigma^{W}>\sigma^{A}$. The model is valid when the crack tip crosses the weld and reaches near weld interface II, $\sigma^{A}$ and $\sigma^{W}$ in that case being replaced by $\sigma^{W}$ and $\sigma^{B}$ respectively resulting in $\Delta K_{\text {tip }}>\Delta K_{\text {applied }}$ since $\sigma^{B}<\sigma^{W}$.

\section{Experimental work}

Bimetallic compact tension specimens were prepared by electron beam welding of $10 \mathrm{~mm}$ thick plates of hot rolled, low strength, ASTM 4340 alloy steel, $A$, and hot rolled, solution annealed, high strength, MDN 250 maraging steel, $B .1 .5 \mathrm{~mm}$ wide ultra strong weld, $W$, was made between the steels such that the weld interface I was at the distance of $48.5 \mathrm{~mm}$ from the right end of the specimen. A notch, $30.5 \mathrm{~mm}$ long and $6.25 \mathrm{~mm}$ wide at the mouth, was machined perpendicular to weld in alloy steel side of the specimens. Fine tip at the notch was obtained by cutting with wire of $0.3 \mathrm{~mm}$ size. A bimetallic specimen is shown in Fig. 3. The specimens were subjected to high cycle tension-tension fatigue load of constant amplitude at ambient environment in $\pm 250 \mathrm{kN}$ capacity material test rig. Details of load cycle were: Maximum load, $F^{\max }=14.7 \mathrm{kN}$, Minimum load, $F^{\min }=$ $0.98 \mathrm{kN}$ and Frequency $=20$ cycles per second. The crack, generated at the notch tip by fatigue precracking, was made to grow till it became critical resulting in specimen fracture. Crack length, $c$, was measured at different positions from the right end of the specimen. Existence of linear elastic regime and non-occurrence of limit load conditions in alloy steel were ensured at each crack position with selected load values under the influence of load transfer. Number of cycles, $N$, required for incremental crack growth were recorded. Crack growth rate, $\mathrm{d} c / \mathrm{d} N$, was computed. Paris law of the form, $\frac{\mathrm{d} c}{\mathrm{~d} N}=C\left[\Delta K_{\text {tip }}(\text { Experimental })\right]^{n}$, was used to obtain experimental values of cyclic 
crack tip stress intensity parameter, $\Delta K_{\text {tip }}$ (Experimental). Constants $C$ and $m$ were found from initial data when the effect of weld interface I had not started.

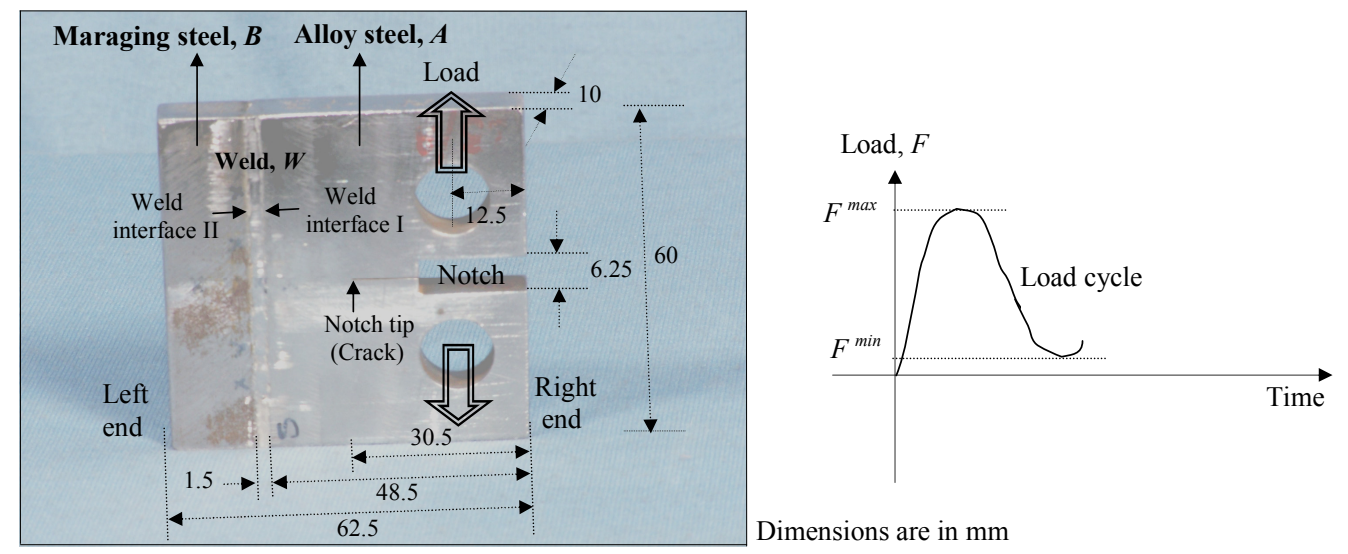

Fig. 3 A bimetallic specimen

Plain specimens of alloy steel with geometry and crack configuration identical with that of bimetallic specimens were fabricated and subjected to similar fatigue load for comparison of crack growth characteristics in them with those in the bimetallic specimens. Fractured specimens are shown in Fig. 4. Micrographs of crack surfaces at fracture locations in bimetallic and plain specimens are displayed in Fig. 5.
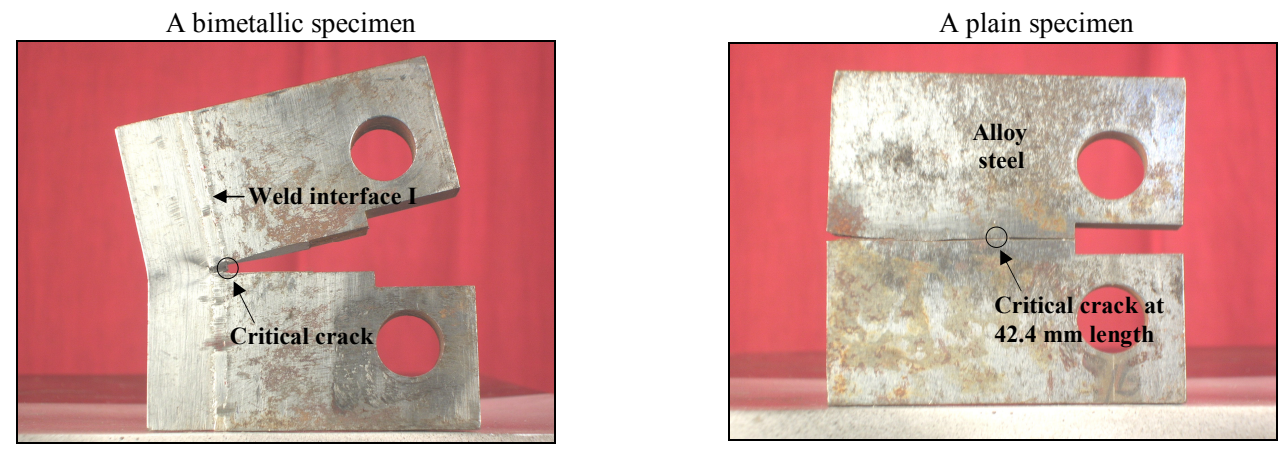

Fig. 4 Fractured specimens

\section{Results}

$\Delta K_{\text {applied }}$ value was determined at each crack position with the help of available empirical formulation for a compact tension specimen. The crack became critical earlier at the length of 42.4 $\mathrm{mm}$ in plain specimen under $\Delta K_{\text {applied }}$ value of $82.42 \mathrm{MPa} \sqrt{\mathrm{m}}$ whereas the crack in a typical bimetallic specimen grew longer up to the length of $48.5 \mathrm{~mm}$ - touched weld interface I, thereby sustaining increased $\Delta K_{\text {applied }}$ value of $147 \mathrm{MPa} \sqrt{\mathrm{m}}$ before becoming critical immediately upon entering into weld as soon as the shielding effect of weld ended. In the process, the fatigue life of bimetallic specimen increased substantially. 29442 cycles were needed for fracture of bimetallic specimen whereas 18309 cycles only caused fracture of plain specimen. This finding clearly demonstrated shielding effect of ultra strong weld over the crack tip in weak alloy steel which manifested in the form of reduced $\Delta K_{t i p}$ values, helping the crack to grow longer before becoming critical. Micrograph of alloy steel near weld interface I in bimetallic specimen, when the specimen had not yet fractured, was different from the micrograph of fractured surface of plain alloy steel specimen which confirmed delayed fracture of bimetallic specimen. Effect of weld interface II was not experienced by the crack since it had already become critical before reaching that interface.

Value of $\Delta r$ for commencement of the effect of weld interface I was estimated as $4.07 \mathrm{~mm}$ at crack length at $44.43 \mathrm{~mm}$. But it was found during experiments that the influence of weld commenced earlier at crack length of $38 \mathrm{~mm}$. This was due to additional load transfer towards stronger materials on other side of weld interface I by eccentric loading over the crack. Correction 
factor for same was applied in the computational model while evaluating $\Delta K_{\text {tip }}$ (Theoretical) at different crack positions. Plane stress and plane strain conditions existed in alloy and in weld respectively for $10 \mathrm{~mm}$ thickness. Computation confirmed that the extent of spread of cohesive zone was restricted to the weld without crossing over into maraging steel since the maximum value of $l$ at crack length of $48.5 \mathrm{~mm}$ was $0.12 \mathrm{~mm}$ which was less than the weld width of $1.5 \mathrm{~mm}$. Plots of $\Delta K_{\text {applied }}$ and $\Delta K_{\text {tip }}$ during crack growth in a typical bimetallic specimen are presented in Fig. 6. Values of $\Delta K_{\text {tip }}\left(\right.$ Theoretical) and $\Delta K_{\text {tip }}$ (Experimental) are found to be in good agreement with each other.
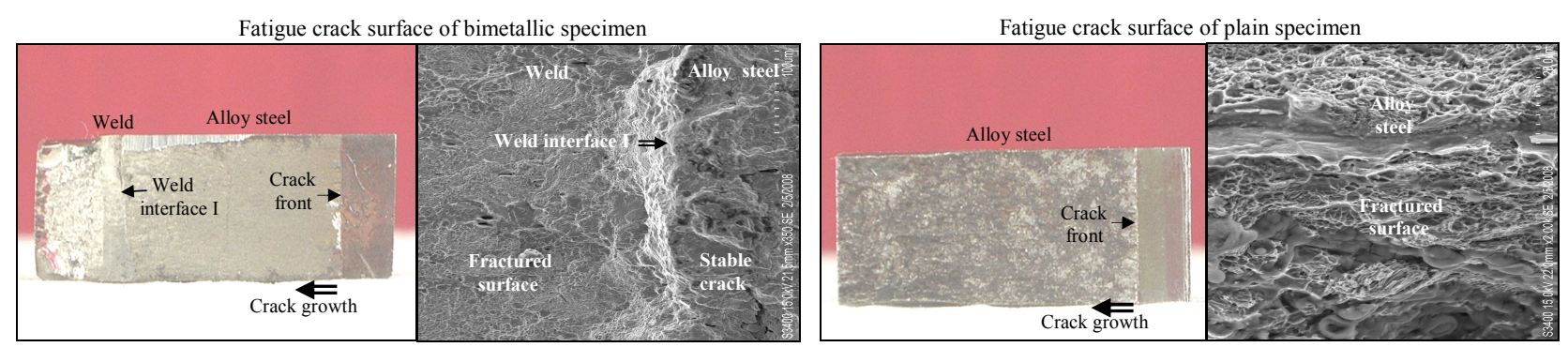

Fig. 5 Micrographs at fracture locations in bimetallic and plain specimens

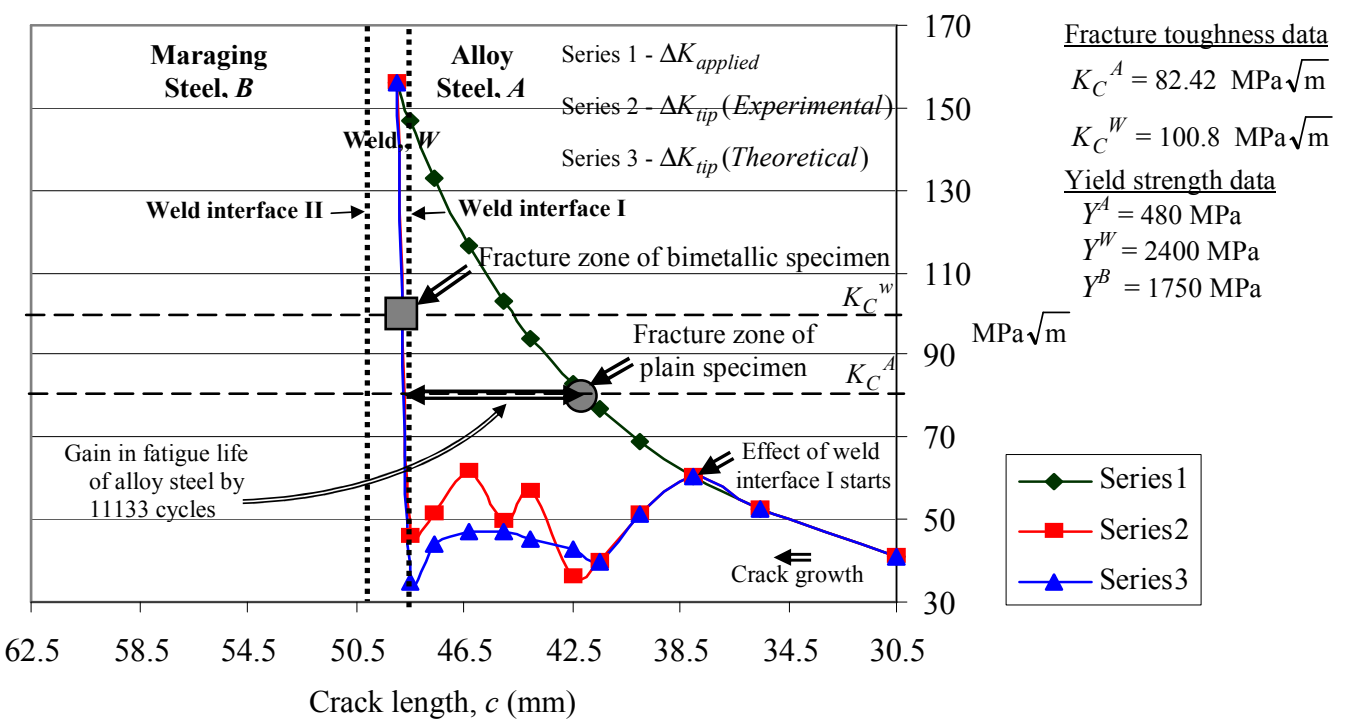

Fig. 6 Plot of stress intensity parameters vs crack length

\section{Conclusion}

Ultra strong weld, between weak alloy and strong maraging steels, in a bimetallic composite shields the advancing fatigue crack tip in alloy steel thereby enhancing the fatigue life of the composite. A computational model for determining $\Delta K_{t i p}$ near a strength mismatched interface in $K$ dominant conditions is validated by experimental work in the paper. With known $\Delta K_{\text {tip }}$ values, number of cycles needed for the crack to become critical or specimen fatigue life can be estimated.

\section{References}

1. Y. Sugimura, P.G. Lim, C.F. Shih and S. Suresh: Fracture normal to a bimaterial interface: Effects of plasticity on crack tip shielding and amplification. Acta Metallurgica et Materialia,Vol. 43 (1995), pp.1157-1169.

2. D.S. Dugdale: Yielding of steel sheets containing slits. Journal of the Mechanics and Physics of Solids, Vol. 8 (1960), pp.100-104.

3. V.G. Ukadgaonker, Sunil Bhat, Mahendra Jha and P.B. Desai: Fatigue crack growth towards the weld interface of alloy and maraging steels. International Journal of Fatigue, Vol. 30 (2008), pp. 689-705. 